BNL $50635 \frac{248}{8-17-14}$

\title{
LAND USE AND ENERGY UTILIZATION
}

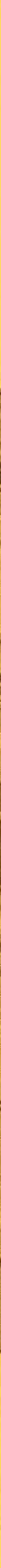




\section{DISCLAIMER}

This report was prepared as an account of work sponsored by an agency of the United States Government. Neither the United States Government nor any agency Thereof, nor any of their employees, makes any warranty, express or implied, or assumes any legal liability or responsibility for the accuracy, completeness, or usefulness of any information, apparatus, product, or process disclosed, or represents that its use would not infringe privately owned rights. Reference herein to any specific commercial product, process, or service by trade name, trademark, manufacturer, or otherwise does not necessarily constitute or imply its endorsement, recommendation, or favoring by the United States Government or any agency thereof. The views and opinions of authors expressed herein do not necessarily state or reflect those of the United States Government or any agency thereof. 


\section{DISCLAIMER}

Portions of this document may be illegible in electronic image products. Images are produced from the best available original document. 
BNL 50635

(Energy Conservation-Systems Modeling and Performance Assessment - TID-4500)

\title{
LAND USE AND ENERGY UTILIZATION
}

\author{
FINAL REPORT
}

T. Owen Carroll, Robert Nathans, and Philip F. Palmedo

June 1977

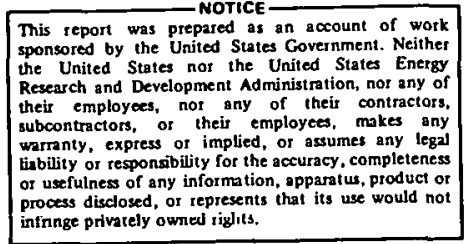

Policy Analysis Division

Institute for Energy Research

National Center for

Analysis of Energy Systems

State University of New York

Brookhaven National Laboratory

Stony Brook, New York 11790

Upton, New York 11973

BNL/SUNY LAND USE AND ENERGY UTILIZATION PROJECT

SPONSORED BY THE OFFICE OF CONSERVATION AND ENVIRONMENT OF THE

FEDERAL ENERGY ADMINISTRATION 


\section{NOTICE}

I'his report was sponsored by the United States Federal Energy Administration. Views and conclusions expressed herein should not be interpreted as the official opinion of the sponsoring agcncy.

Printed in the United States of America Available from

National Technical Information Service

U.S. Department of Commerce

5285 Port Royal Road

Springfield, VA 22161

Price: Printed Copy $\$ 4.00$; Microfiche $\$ 3.00$

June 1977

650 copies 


\section{$\underline{\text { Abstract }}$}

Land use plays an important role in structuring the basic patterns in which energy is consumed in many areas of the United States. Thus, in considering policies at a national or local level, which are aimed at either utilizing energy supplies in a more efficient manner, or in establishing the compatibility of new energy supply, conversion and end use technologies with our existing social patterns of energy use, it is important to understand the interdependencles between land use and energy.

The Land Use-Energy Utilization Project, initiated in July 1974 with support from the Office of Conservation and Environment of the Federal Energy Administration, was designed to explore the quantitative relationships between alternative regional land use patterns and their resultant energy and fuel demands and the impacts of these demands on the regional and national energy supply-distribution systems. The project studies and analyses described briefly in this report provide

- a framework for delineating the energy system impacts of current and projected regional land use development.

- a base of information dealing with the energy intensiveness of assorted land use activities.

- models which enable federal and regional planners to estimate the ranges of potential energy saving which could be derived from employing alternative land use activity configurations.

- a user manual, based on the above, for allowing local land use planners to carry out their own land use-energy impact evaluations.

Much remains to be done to elucidate the complicated interdependencies between land use and energy utilization. What we have accomplished is an Initial scructuring of the problem. Un the other hand, the recent increase in interest in establishing new ways for the United States to achieve energy conservation suggests that actions will be taken in the near future to tie land use development to national and local targets for conservation. Consequently, we outline a future agenda of research, data collection, demonstration, and policyrelated efforts aimed at both increasing our understanding of the land use-energy equation and at effecting changes in current land use planning practices. 
THIS PAGE

\section{WAS INTENTIONALLY LEFT BLANK}


TABLE OF CONTENTS

Page

I. Introduction ............... . 1

II. Energy and Land Use Planning . . . . . . 5

A. Systems Framework for Structuring

Land Use-Energy Interdependence. . . 7

III. Major Results of the Land Use-Energy

Utilization Project . . . . . . . . . 13

A. Systems Framework .. . . . . 14

B. Energy Intensity Factors . . . . . 16

C. Land Use-Energy Simulation Model . . 22

D. Planners' Energy Workbook . . . . 25

E. Energy Assessment of Land Use Development Plans . . . . . . 31

IV. Future Direction for Land Use-Energy

Utilization Efforts . . . . . . . . . 39

A. Land Use-Energy Analysis

Demonstrations . . . . . . . 39

B. Guidelines for Energy Conserving

Land Use Development . . . . . . . 39

C. Energy Accounting Measures and Indices.... . . . . . . . 40

D. Energy-Land Use Relationships and Environmental Factors ..... 40

E. Land Use and New Energy Technologies........... 4I

F. National Land Use Trends and Projected National Energy Demands. . . 41

G. Lifestyle Analysis . . . . . . . 42

V. Future Significance of Land Use
and Energy Utilization Analysis . . . . . 43 
I. Residential Energy Demand......... 19

II. Industrial Energy - Employment Land Use . . . . . . . . . . . . 20

III. Residential and Transportation Abstracts of Worksheets . . . . . . . 27

IV. Summary of Land Use Scenario for Nassau-Suffolk . • . . . . . • . 35

\section{FIGURES}

1. Framework for Search and Selection of Energy-Conierving Land. Use Yatterns . . . . . . . . . . . . 10

2. Land Use and Energy Utilization Model . . 23 


\section{INTRODUCTION}

Land use plays an important role in structuring the basic patterns in which energy is consumed in many areas of the United States. The uses to. which land is put and their spatial arrangement with respect to one another can also influence the energy technologies and the production, conversion and distribution facilities which are utilized to provide the final energy to residential, commercial, and industrial users. Thus, in considering policies at a national or local level, which are aimed at either utilizing energy supplies in a more efficient manner, or in establishing the compatibility of new energy supply, conversion and end use technologies with our existing social patterns of energy use, it is important to understand the interdependencies between land use and energy.

The Land Use-Energy Utilization Project, initiated in July 1974 with support from the Office of Conservation and Environment of the Federal Energy Administration, was designed to explore the quantitative relationships between alternative regional land use patterns and their resultant energy and fuel demands and the impacts of these demands on the regional and national energy supply-distribution systems. More specifically, it was intended that the project studies and analyses would result in:

I. a framework for delineating the energy system impacts of current and projected regional land use development.

2. a base of information dealing with the energy intensiveness of assorted land use activities.

3. models which would enable federal and regional planners to estimate the ranges of potential energy saving which could be derived from employing alternative land use activity configurations.

4. a user manual, based on the above, for allowing local land use planners to carry out their own land use-energy impact evaluations. 
Several reports and papers have been issued during the course of the project dealing with each of these objectives. The most inclusive of these are:

1. Land Use and Energy Utilization: Interim Report

This report describes the conceptual framework used to analyze the complex interrelationships between regional growth parameters, land use preferences, and constraining characteristics of the regions' physical terrain and pertinent energy-related factors. The report also contains an exposition of the basic methods used to evaluale lhe energy intensity fuctors associated with specific land use activities. F'inally, it includes a case study illustrating the applicability of the framework and land use/ energy intensity factors to a specific region - the Nassau-Suffolk area of Long Island.

2. Land Use-Energy Simulation Model - A Computer-Based Model for Exploring Land Use and Energy Relationships

The basic model developed during the course of the project is presented in this report. That model employs the basic structure of the Lowry land use model to develop a variant which captures the significant energy sensitive elements in regional land use development. The report describes the model components, shows how it is capable of generating the basic structural elements in the land use-energy demand equation, and presents several exumpleis to demonstratc ito applicability.

3. The Planner's Tnergy Workbook - A User's Manual for Exploring Land Use and Energy Utilization Relationships

Aimed primarily at regional and local planners, this report describes the framework for land use-energy utilization analysis and goes on to describe step-by-step procedures which planners can utilize to carry out energy demand and fuel analyses based on land development in lieir own communities. Worksheets, energy intensity intormation, and lislings of local and national energy data sources are presented in the report. Finally, by way of illustrating the uses of the basic information offered in the body of the report, the results of energy analysis calculations based on real data for a large region and a small community are presented. 
In this final report, we summarize briefly the important findings of the project and indicate future directions for policy-related research in this area. Details of the models and analyses are all contained in the other three reports noted above. 
THIS PAGE

\section{WAS INTENTIONALLY} LEFT BLANK 


\section{ENERGY AND LAND USE PLANNING}

The nature of a nation's pattern of energy consumption is a product of many factors - the prevailing life-style of its citizens, its institutions, and the historical development of its energy supply-distribution system. Several analyses of energy consumption in other industrialized countries, which on a per capita basis consume significantly less energy than the United States, have revealed a number of subtle complexities in the interconnecting linkages. While land use patterns are, in a sense, a structural manifestation of these and other societal factors, in considering Iong term policies aimed at either reducing future energy demands in the United States or insuring their compatibility with alternative energy technologies being developed, land use offers a unique instrument for bringing about a major alteration in national enerby consumption.

To understand the importance of the land use component in setting the basic pattern of the nation's residential and transportation energy expenditures, one must consider the basic decision elements which affect total life-time energy consumption for most households in the United. States. From a policy perspective, the significant descriptors of these decision elements are 1) the implications with respect to fraction of the total life-time energy consumed by the household as a result of the decision, and 2) the time intervals between the recurrence of such decisions. Viewed within this context, the choice of site for a household residence in a region, its size, and its construction type represent perhaps the key decisions which will determine overall life-time transportation and space energy consumption for the household. Moreover, once made, the energy consequences of such decisions remain in effect for the inhabitable life-time of the dwelling - some 40 years on the average. The same reasoning holds true for the location and mix of regional and/or community, industrial, and commercial activilies.

On the other hand, household decisions with respect to the size, 
number, and type of automobiles, major and minor appliances, and energy consumed in disposables, will not only affect total life-time household consumption less significantly but involve decisions made on a recurring basis every few years.

For both local and national policy makers concerned with energy, these differences pose a fundamental dilemma. It is clear that the energy savings derived from initiatives directed toward influencing the recurring household decisions will be more productive of results in the short term. On the other hand, if these initiatives are not accompanied by other actions which ofter, for example, actions to limit the sprawl of urban areas, they will leave untouched the major determinants of national energy growth.

Land use planning in the United States over the past several decades has been influenced by a shifting set of practical and aesthetic concerns such as environmental pollution, interest in providing housing to low and middle income groups, and the retention of large open spaces and farm land. These concerns have been reflected in the development of new areas and the redevelopment of inner cities, in zoning decisions affecting the siting of residential, commercial, and industrial activities, and in the location and choice of mass transportation systems and road networks. A necessary preliminary to obtaining land use decisions that lend weight to these different societal interests is the formulation of a quantitative methodological basis for elucidating the impacts of alternative policies on land use arrangements and/or the effects of a variety of land use arrangements on the issue on hand. In the case of energy, such a methodology must be aimed at relating the production and use of energy in a region to the mix and spatial arrangement of each of the major land use activities - residential, commercial, industrial, and transportation. To be used effectively as a land use planning tool, such a methodology must not only be able to establish the dependence of energy demand on alternative land use configurations, but must pose these interrelationships in a manner which reveals the interdependency between this demand and the regional and national system of energy supply and distribution. Moreover, the methodology 
must be sufficiently general to permit its use under a wide variety of conditions attendant to the use of land in different parts of the country and the prevailing uses of different energy fuels and technologies. Finally, procedures must be derivable from the methodology which allow its use by planning groups with little or no technical background in energy systems or technologies. Our approach used in exploring the relationships between energy utilization and land use is reflected in a generalized systems framework which includes all these considerations. A. Systems Framework for Formulating Land Use-Energy Relationships * Figure 1 shows in diagramatic form the conceptual framework we have utilized for analysis of the relationships between land use development goals, preferences, and constraints and their regional and national energy implications. This diagram identifies the basic elements which enter the land use-energy linkages and those points in the system where intervening strategies and measures are likely to bring about changes in existing energy use practices and land use development trends. As seen in the figure, our approach acknowledges that the primary driving forces which define the mix, levels, and spatial arrangement of land use activities in a region are most often found to be exogenous to energy considerations. They result from a variety of external economic, social, and political conditions, many of which are set by factors beyond the control of the region. Some of these, however, are identifiable targets or goals for regional development, such as population, employment, and industrial growth. Regional preferences with respect to industrial development, mix of activities, zoning, open space, etc., álso enter into regional development, as do certain physical characteristics of the terrain and existing land uses.

A knowledge of these regional development parameters and descriptors does not, in general, yield a set of land use activities which is defined with sufficient precision to assess the projected energy demand. The purpose of the land use-energy simulation model is to provide this allo-

T.0. Carroll, et al., Land Use and Energy Utilization: Interim Report, BNL/SUNY Report, BNL 20577 (October 1975). 
cation for each of the major land use sectors - residential, commercial, industrial, and transportation and to partition the end-use sectors among the available space in the region in a manner that is consistent with regional development goals and constraints. Once this detailed set of land use activities is obtained from the model, one can evaluate the projected energy demand for the region utilizing the energy intensity coefficients associated with each subsector of land use activity.

The specification of energy intensity must both relate to conventional land use categories used by planners and be consistent with the varying manner in which energy is consumed by these activities. The output of the land use-energy simulation model is a set of energy demands associated with residential, commercial, industrial, and transportation activities of the projected lanc use configuration.

The designation of specific fuels for individual end use sectors and of the mix of fuels needed to supply these regional energy demands is a product of three interacting factors. First, selected technologies are utilized to (meet the end use demand for energy. For example, to) provide the services of personal travel, the region may rely primarily upon the use of conventionally-powered automobiles. Given the energy efficiency of these vehicles, we can project the amount of gasoline that will be required to meet the regional energy demands specified by the land use-energy model oulputs. Second is the regional energy supply-distribution systems, which may act to limit the total amounts of fuels available to the region. Gasoline deliveries to the region, for example, may be limited by import facilities or pipeline capacities. Since the production, processing, and distribution of energy are themselves land use activities, and have their associated environmental effects, regional preferences exert an influence on the choice of sites for their location and the energy conversion tcchnologies used, for example, nuclear versus coal-firea elechric generating station. The lhiru factor is the national energy system. Through policies affecting energy prices, the availablility of specific fuel. types, and choice of energy supply technologies, this system operates to influence the regional supply-distribution system, end-use technologies, and land uses. 
To analyze these regional and national energy system impacts on fuel demands and to insure that an internally consistent set of data and information is used to describe these systems, we utilize the models and data formats which have been developed at Brookhaven National Laboratory for national and regional assessments. Since the output of the project is designed to be used as a planning tool for local and state land use planners and federal policymakers, the policy variables in the systems framework were chosen to reflect regional development parameters such as location of new industry, residential zoning, and certain characteristics of the transportation sector which are of direct interest to the planner. It also includes regional development goals such as desired levels of population, employment, and housing mix. At the same time, the framework components contain explicit identification of the basic descriptors of each land use activity which will account for the magnitude and form of its associated energy demands.

Characterizing and quantifying the special relationships between the level, mix, and spatial arrangement of land uses and their energy demands requires that we formulate a system of differentiating land use activities which (1) is familiar to land use planners, (2) is able to reflect the varying levels of economic development in the region, (3) displays their relative contributions to total regional energy demands, or to the demands on particular fuel types, (4) distinguishes between activities which are more apt to respond to available energy supplies, and (5) allows the effectiveness of energy conserving technical process to be included. It also requires that we seek varying levels of aggregation of land use activities in the individual sectors which (I) are compatible with the limited nature of available data, (2) utilize available submodels to estimate the effects of regional differences in climate, energy use practices, and construction types on energy demand, (3) allow where necessary the specification of individual fuels needed to satisfy the services for which the energy is employed, and. (4) yield values for the energy intensity factors which are relatively constant throughout the region.

In the land use-energy simulation model, for example, each major sector of land use activities is subdivided into a number of categories, and 


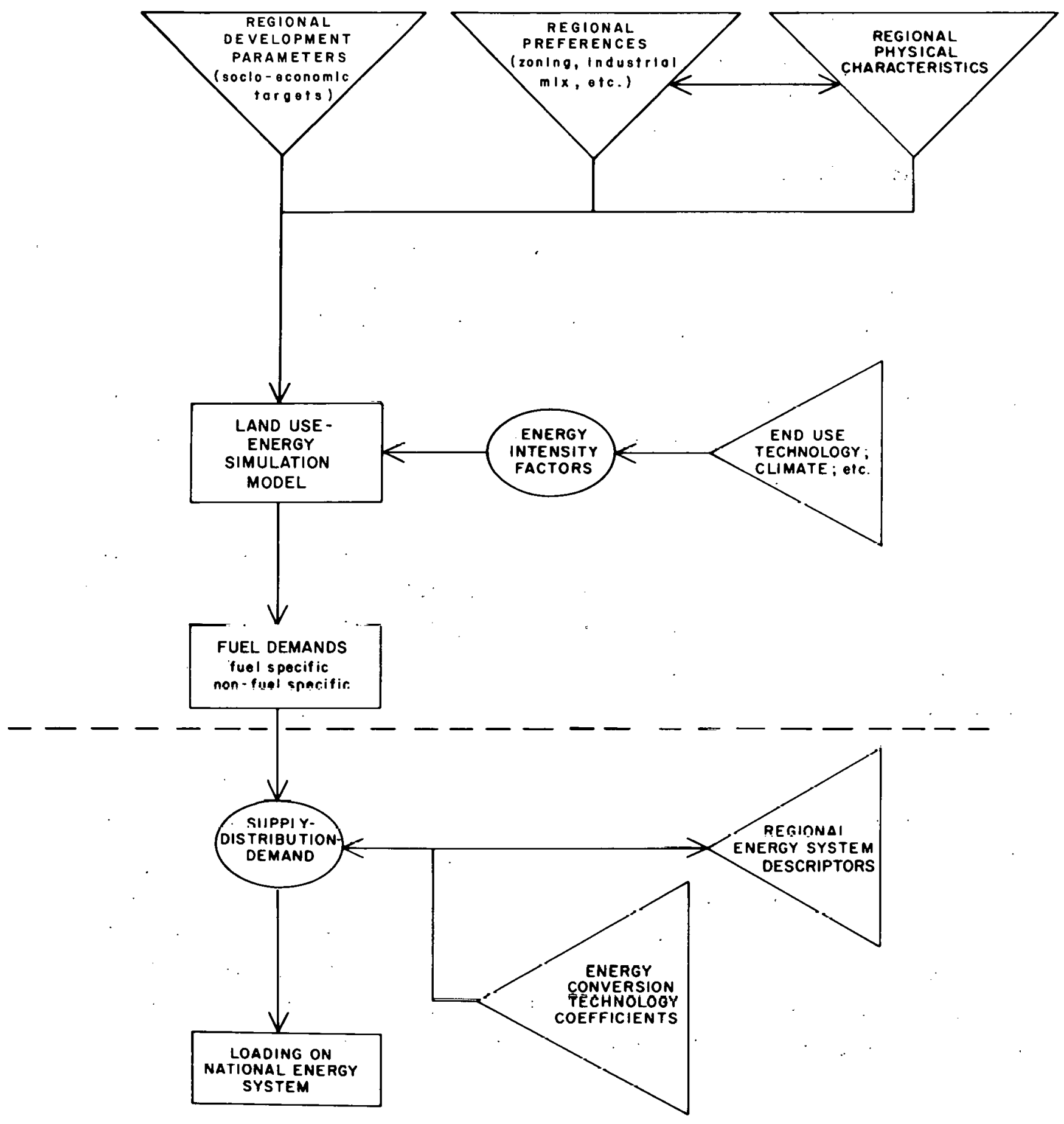

Figure 1. Framework for search and selection of energyconserving land use patterns. 
their energy and fuel specific demands are estimated on the basis of surveys of existing information and data sources. The energy demands per unit activity, which are the land use-energy intensity factors, thus represent average values for a composite set of end use services within the land use activity category for which energy is being consumed. The energy intensity factor for the single-family dwelling category, for example, contains information specific to the region on average energy consumption for space heat, air conditioning, and major and minor appliances. To cast these land use-energy demands in terms familiar to planners, we use different units in different land use sectors - dwelling unit in the residential sector, square footage in the commercial sector, valueadded or number of employees in the industrial sector, and vehicle miles in the transportation sector. The spatial element in specifying the final land use pattern is captured in the transportation sector of the model which takes into account both the existing transportation network and knowledge of national and regional travel patterns.

The application of the system framework shown in Figure 1 usually consists of three basic steps:

1. a "business-as-usual case" is prepared in which the input parameters, such as zoning and industrial development, to the land use-energy simulation model represent a continuation of present trends. The resulting energy and fuel demands are then compared with the energy availability from the regional energy supply system. Loadings on the national energy system are estimated.

2. Alterations, for example, zoning changes, are then introduced into the inputs of the land use-energy simulation model which result in a changed land use pattern and set of energy end use demands which are differentiated between fuel specific and non-fuel specific demands.

3. The supply-demand modeis can then be used to determine minimum cost fuel allocation to meet these demands. Included in these models are any constraints imposed by regional preferences, the 


\section{energy production and conversion technologies utilized, and national supply availabilities.}

A more detailed discussion of the data and information base to support such applications of the systems framework. is contained in the next section of this report. 
III. MAJOR RESULTS OF THE IAND USE-ENERGY UTILIZATION STUDY

Two types of results have been forthcoming from this study of land use and energy utilization. The first are methodological. These include

- the systems framework for structuring the linkages between regional and/or community development and the energy system.

- the energy intensity factors which connect total energy demand and fuel specification characteristics with a relatively limited set of discrete land use activities.

- the land use-energy simulation computer model which captures the essential interrelationships beteen alternative land use development patterns and the character and magnitude of the resulting energy demand.

- the simplified procedures presented in The Planner's Energy Workbook which allow planners to assess the energy implications of their own regional or community development plans.

A second type of result to come out of the study is of a more general nature. It includes

- the estimates of specific energy savings which are obtainable if energy conserving land use designs are employed.

- generic conclusions which relate to the character of land use-energy utilization interrelationships.

- a tentative agenda based on the above for future policyrelated research and action in this area.

In the sections that follow, we summarize the significant features of each of these major results and discuss some of the difficulties likely to be cncountcred in their utilization. 
A. Systems Framework

The systems framework, which is summarized in the preceeding section of this report, utilizes reasoning similar to that found in a variety of environmental-land use models. Both employ activity models to generate output levels in the factors of interest. In the energy case, these are the total average energy demand and the fuel specific character of the demand where such can be defined.

From a policy perspective, a basic difficulty in the formulation of the energy-land use activity equation is lise luck of eusily established and measured indices to express societal concerns in a cost-benetit context equivalent to the indices of ambient air and water quality in the environmental case. Considerabile thought was given to the possibility of formulating such energy indices or measures. The concept of a regional energy budget, based on total energy demand generated by current and projected land use activities, was considered and discarded because of the difficulties that would be encountered in taking into consideration the filow of energy into and out of the region in the form of embodied energy and because energy budgets would be difficult to enforce.

The notion that the regional and national energy supply-distribution constraints related to regional land use be used to act as restraining influences on regional development that is wasteful in energy, although not amenable to defining in terms of a simple set of indices, does allow regions and the federal government to establish some basis for weighing the costs and benefits of land use actions. For example, the benefits of allowing zoning which permits higher density land use may appear as a reduced need for the construction of local electric generating stations. On the other hand, a decision to employ decentralized advanced utility systems requires the adoption of certain changes in current zoning laws with respect to interspersion of land use activities. However, a Ilmilaliun in using this coupling between land use activities associated with energy

*

T.O Carroll, et al., The Planners Energy Workbook, BNL/SUNY Report, BNL 50633 (December 1976). 
supply and distribution and those associated with the generation of additional demands is that no single region of the country is self sufficient in energy. Moreover, it may or may not be desirable that they aim to be so. Also, as in the case of the energy budget, to be completely effective such an approach should include energy flow accounts into and out of the region. Although there is no simple solution to this problem, it is quite evident from the systems framework that some sort of standards must be set by federal and state governments which require individual regions and communities to make land use planning decisions commensurate with producing a better balance between energy supply and demand. Otherwise, there is little incentive on the part of individual regions or communities to utilize their land use planning powers to reduce energy expenditures.

Another feature revealed by the systems framework is the decoupling. between decision- and policy-making bodies who have traditionally borne primary responsibility for the siting of power plants and refineries, location of transmission lines, and pricing of electricity and the local officials and planning groups who are responsible for zoning decisions. Moreover, both groups are at the mercy of federal agencies who determine the supply of primary fuels coming into the region, set national prices for essential fuels, and make investments in new energy technologies. This fragmented jurisdictional situation makes it difficult to formulate integrated policy strategies directed toward producing land use patterns which are "optimal" for the region, the state, and the nation, and also may account in some measure for the disparity between the lower energy per capita consumption fourd in such countries as Sweden and West Germany compared to that in the United States.

In formulating the basic land use-energy utilization relationships, our framework emphasizes that energy production and use constitutes only one of numerous contributing factors in determining the final form of land. use development. The purpose of land use energy analysis is thus not to determine energy "opt1mal" land use configurations, but to assess the impact of a variety of designs and plans on the energy system and viceversa. In certain cases, where the supply of energy to the locale is 
either uncertain or is associated with unwanted risks or environmental degradation, this framework allows the trade-off between alternative land use arrangements and supply options to be compared. In other cases, where the conservation of energy is considered to be a primary objective, the methodologies can be used to establish the overall energy budget of the region in question. In all such cases, it must be implicitly assumed that area-specific economic, political, aesthetic, and social elements remain the fundamental driving forces for land use development. Energy itself is seldom the prime issue. What is required is an assessment of the energyanvirnnmentail implicatiuns of land use.

There are certain limiations in our framework which are important to note. It is not designed to be used to deal with communities smaller than perhaps several thousand population, particularly when these communities lie within a larger metropolitan area. In such cases, the flow of energy in and out of the region vis-a-vis the movement of goods, services, and people prevents any detailed energy analysis of land use alternatives without a consideration of the larger surrounding area. The methodology is also of limited use in considering short-term, highly detailed questions such as the energy impacts of new apartment complexes or industrial parks. These types of analyses are highly dependent on the specific type of construction or industrial processes employed. However, the methods can be utilized to assess the overall impact of such development on regional fuel supplies and distribution and their compatibility with other energy expenditures in the community.

\section{B. Energy Intensity Factors}

A key feature of the methodology used in this proejct is the adoption of the use of energy intensity factors to characterize the energy and fuel demands for different land use activities. However, eriergy demande for certain land use activities vary, for example, with climule, with energy usage habits, with manufacturing processes, and with income group. Furthermore, the models used to evaluate energy demands per unit of activity

T.0.Carroll, et al., The Planners' Energy Workbook, BNL/SUNY Report, BNL 50633 
level can range from the simple "black box" type of representation to elaborate descriptive models which account for each separate activity making up the composite.

In this preliminary stage of the development of the land use-energy equation, we have opted for the black box approach. In this approach, each major sector of land use activities is subdivided into a number of distinct categories and their energy demands estimated on the basis of surveys of existing information and data sources. The energy demands per unit, which are the energy intensity factors, thus represent the averaged energy demands of a set of aggregated activities. . The units used to express the energy intensity factor will also vary from sector to sector. For the residential sector, we use dwelling as the unit; in. the commercial sector, square footage is used; in. the industrial sector, the unit is either industrial dollar value-added or employees; in the transportation sector, vehicle miles traveled is used.

Regional differences of energy intensity factors in the residential and commercial sectors which relate to changes in climate, building construction and average size, are introduced into the energy intensity factors through the use of engineering submodels. Energy intensity factors in the industrial and transportation sector represent values based on national averages. Again using the analogy with the environmental-land use methodologies, energy intensity factors or coefficients parallel the emission factors which characterize pollutants generated in terms of their quantity and chemical and physical composition per unit output of goods and/or services associated with each land, use activity.

It is important to understand that in attempting to capture the essential energy features of individual land use activities in a single factor, we are statistically aggregating a set of separate activities, each of which consumes energy. In general, the energy consumed will depend on the physical cnvironmeut in which the energy consumption takes place, the level of service or goods being produced ac a resull of the consuming activity, the processes and devices employed, and finally, energy lisage customs of the users. 
Statistical averages of energy demands or energy intensity factors for individual land use activities represent area composite mixtures of all of these ingredients. For example, in the case of single family dwellings, they include houses of a variety of sizes and construction types, inhabited by families of different sizes and incomes, owning different types and numbers of appliances and with different energy usage customs. Similar variations exist among industrial users and in the transportation and commercial sector.

Civen this viriation, considerable care must be taken in defining and calibrating energy intensity factors for use in a specific rcgion. Furthermore, because energy intensity factors represent statistically averaged quantities, they tend to be more accurate if applied on a regional rather than a community scale. It is possible to systemize the calibration procedures and validity checks. In the Planners' Energy Workbook, we have a set of simplified procedures and worksheets which should enable local planners to make their own evaluations. For example, an abstract of the energy demand structure for the residential sector is shown in Table $I$. The energy demand for heating and cooling requirements per degree day in this example reflects standard building practices for new construction. These energy requirements are combined with regionspecific heating and cooling season degree-day data, which may be taken from maps in the workbook, to establish energy intensity factors per dwelling unit, or unit energy demands. Where size, insulation requirements, or other characteristics of regional housing differ markedly from the standards defined in the workbook, calibration procedures such as that shown in Table I are identified along with data sources, graphs, and other information necessary to carry out the prucedurea. The character of energy demands in the industrial sector are similarly described in terms of energy intensity, us in Table II. Fuch enerpy intensity factors are based upon the detailed study of energy end use demands and fuel consumption patterns in each sector, and an identification of region-specific inputs required to yileld the set of energy intensity factors.

In defining energy intensity factors, we have restricted our consideru- 


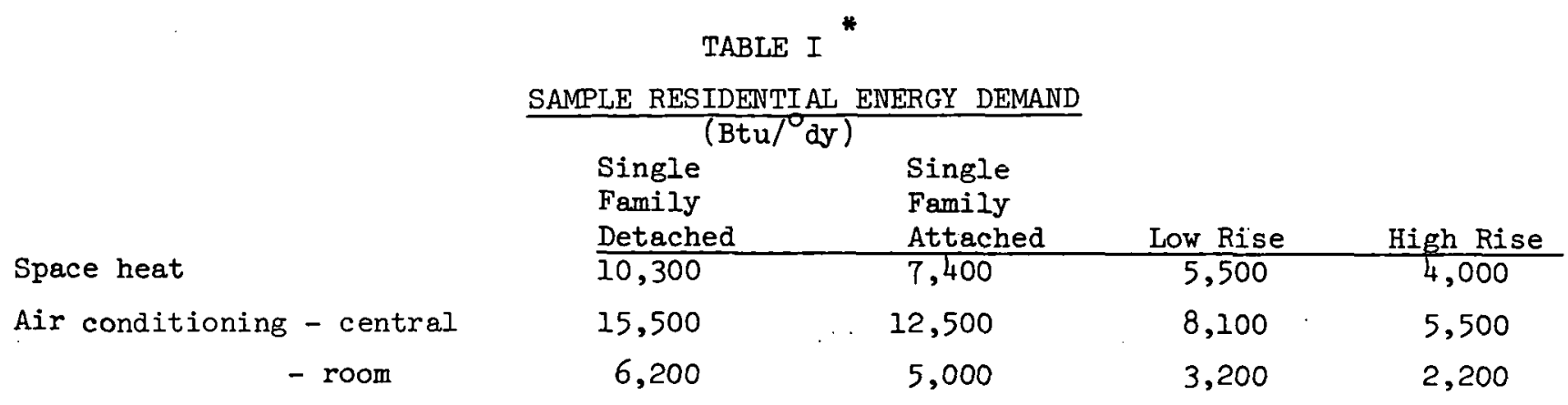

SAMPLE CALIBRATION

Nominal Heat Demand (Btu/ $\left.{ }^{\circ} \mathrm{dy}\right)$ (1300 sq. ft)

10,300

7,400

5,500

4,000

a. Size Coefficient

(Btu/ ${ }^{\circ}$ dy per sq.ft.)

5.6

4.4

2.9

1.6

b. Size Increment

(sq.ft.)

200

c. Adjustment $(a \times b)$

1120

Region-specific Heat Demand (Btu/ $\left.{ }^{\circ} \mathrm{dy}\right)$

11,420

(1500 sq. ft.)

Based upon tables in The Planners' Energy Workbook. 
TABLE II

INDUSTRIAL ENERGY - EMPLOYMENT - IAND USE

\begin{tabular}{lllll} 
& Energy Per & Employee Per & Energy Per \\
& Dollar Value & Dollar Value & Employee & \\
Industry & Added & Added & (Million & Energy Per Acre \\
Group & (Thousand Btu/\$) & (Emp/Mill. \$VA) & Btu/Emp) & (Million Btu/Acre) \\
\hline
\end{tabular}

Light

Industry

10.5

90

120

3360

28

Medium

Industry

32

100

310

8680

28

Mining \&

Metals

72

59

1170

9360

0

Paper \&

Chemicals

129

62

.1710

1,3680

8

Synthetics

46

16 
tion to energy demand generated in the normal operation of devices employed to yield to the final demand for goods and services. Not included are the embodied energy content of material input or output. While acknowledging the importance of the embodied energy content of materials and devices in the land use-energy relationship, were we to have this component, it would have vastly increased the complexity of the analysis and made it unfeasible to prepare documentation for allowing planners to prepare their own assessments. Moreover, to the extent that local planning choices exert relatively little control over the types of material imported into or utilized in the region, the inclusion of such information would be of little import to local land use decisions. On the other hand, in considering the energy trade-offs between alternative land use configurations from a national perspective, it is essential to include such considerations. The values estimated for the energy intensity factors are valid only as long as they remain relatively constant throughout the region for a similar land use activity included in the given category. For residential and commercial land use activities, this appears to hold true for a relatively limited subset of categories within each sector. There is considerably more uncertainty attached to the industrial and transportation sectors. In the industrial sector, one attempts to cluster industry types according to both their total energy demands and fuel usages. This procedure appears to be valid except for the most energy intensive industries which must be treated on an individual basis. In the transportation sector, we utilize a heuristic approach based on a combination of local and national data sources which assumes the spatial distribution of land use activities plays a dominant role. Except for areas lying far apart from urban centers this procedure appears to give reasonably good values. We should note, however, that these kinds of approaches do not apply to commercial travel. Such travel is much more difficult to capture in a single intensity factor.

The validation checks on energy intensity factors roquire duta that is specific to the region under examination. Because energy information is normally not included in many local data sources, it is necessary in many cases to use surrogate measures combined with nationally average values to 
deduce the required information. Although an attempt was made in our formulation of energy intensity factors to cast them in terms which could utilize information normally available to the land use planner, there is little doubt that some familiarity with the technical aspects of energy analysis will be required in utilizing the procedures for assembling a set of locally validated energy intensity factors. Presumably, if energy considerations become a regular input to land use planning, better sources of direct local information will become available. C. Land Use-Ertergy Eimulatinn Model

The Land Use-Energy Simulation Model, which we have developed as a part of this study, is an extension of the classic Lowry model. It represents a modification of the Lowry model in several important ways. The housing, commercial, and industrial sectors are disaggregated into subsectors suitable for energy demand calculations by an energy submodel. The Lowry algorithm for the distribution of residential activity has been modified to enable consistenl computation nf work trip patterns. Network algorithms are used to establish intertract travel times and distances. Such a model framework captures two essential features of the land use-ewergy utilization interaction:

- the spatial location of land use activity is explicit,

- transportation energy demand is determined as an integral part of the fpatial configuration.

The land use-energy simulation model itself is divided both conceptualiy and computationally into three parts: the land use model shown by the bold lines in Figure 2, a submodel for transportation which provides the work and shop trip distribution for spatial allocation of activities within the land use submodel, and an energy submodel which determines energy demand resulting from the land use configuration.

Regional growth in the model is Frericated upon an industrial employment base and the existing transportation infrastructure. Site-specific

T. O. Carroll, et al., Land Use-Energy Simulation Model, BNL/SUNY Report, BNL-50634 


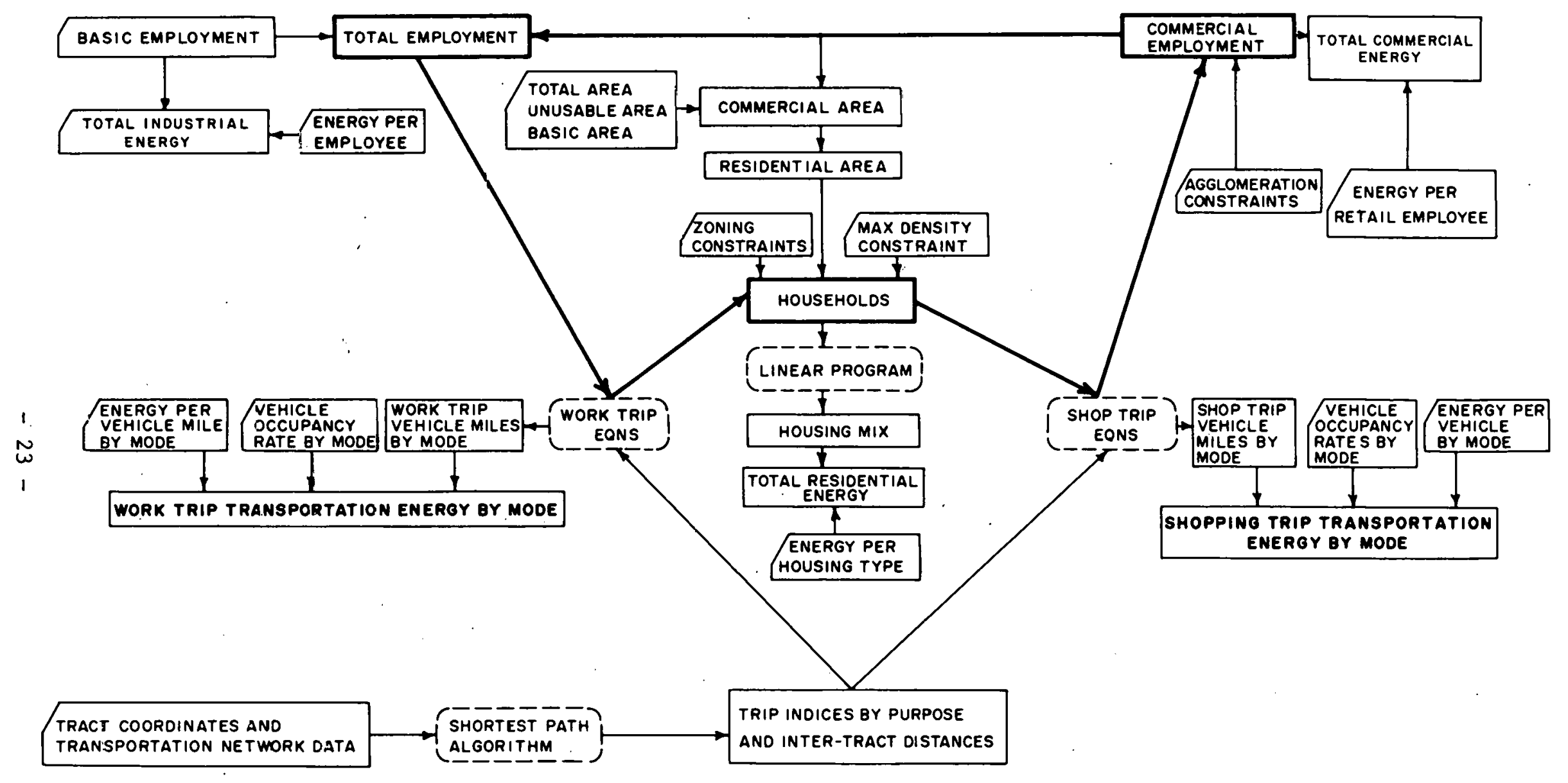

Figure 2. Land use and energy utilization model. 
manufacturing and other industry dependent upon the interregional transportation network or the availability of local resources is termed "basic" industry. All employment located outside the region is also considered "basic". The region is divided into tracts, and for basic industry, the employment and acreage are specified for each tract. Using a trip distribution function derived from the transportation network, which measures preference for travel in the region, a residential population is spatially allocated consistent with industrial employment opportunties. Rctail and nther commercial activity, such as offices and school, measured by employment opportunities are also spatially distributed using the characteristics of the transportation network for residential-commercial travel. Zoning and measures of agglomeration are expressed as constraints upon location of activities in specified tracts. The sequence of regional development is portrayed through appropriate intervention into growth in industrial employment, zoning changes, housing mix, and modifications in the transportation network representation.

The model is adapted to the determination of energy demands in several important respects. The residential sector is disaggregated into types of housing with old and new housing stocks for which energy demands differ significantly. This facilitates examining the impact of the siigle/multifamily housing mix, whose complexity is lepresented in residential zoningemployment-travel interactions in the spatial allocation process. A Jinear program is utilized to establish the housing $\mathrm{mlx}$ in each tract, in which the objective function expresses preferences for each type of housing in the tract and the constraints reflect zoning restrictions and land availability. Commercial sector energy is similarly associated with different types of retali activity. Industrial. sector energy is determined through bacio industrial employment in the region.

Trumsportation energy ie determined directly in the model. since lhe actual spatial allocation is tempered by zoning and agglomeration factors, the resulting land use configuration reflects the "constrained preferences" of residents with respect to travel. Actual industrial-residentialcommercial travel assignments by tract, trip distribution for different purposes, and vehicle occupancy rates are utilized in the calculation of 
passenger miles of travel and energy consumption. Modal split may be integrated into the model through specific grid assignments with alternative modes of transportation. Overall, the spatial land use configuration both determines and is determined by the transportation network so that travel patterns and associated energy demand are explicit.

The model was calibrated and tested on the Nassau-Suffolk region with overall results similar to those described later in the report which were based upon The Planners' Energy Workbook. The computer model proves most valuable in its capability to easily simulate a variety of zoning changes and other land use decisions along with their energy implications. In this application, a broad range of spatial land use patterns can be sifted to identify those most compatible with energy and other regional development concerns. Also, the model is particularly useful in exploring the transportation requirements and energy consumption for work, shopping, and other purposes assoclated with alternative land use patterns.

\section{The Planners' Energy Workbook *}

This workbook was designed to present a straightforward set of calculational procedures and worksheets which community planners and designers can use to carry out their own evaluation of alternative land use planning and design programs. It describes the structure of the methodology for relating energy utilization to land use activity levels and configurations for each major end-use sector. These are expressed in terms related to such factors as local climate, industrial employment, distance from urban core, and fuel type for end use devices existing in the home. An integrating worksheet format is provided to simplify the use of energy-land use design criteria and to estimate energy consumption profiles for the area in question. Examples are provided to illustrate the trade-offs in terms of alternative uses of land in both urban and suburban settings. The procedures used in The Planners' Energy Workbook were chooen not to require the use of computers.

T.0. Carroll, et al., The Planners' Energy Workbook, BNL/SUNY Report. BNL 50633 
The starting point for the analysis in the workbook is a set of land use activities which consist of a definition of their end use mix and spatial distribution for the area under consideration. This may be obtained from a design or plan being considered, an extrapolation of current trends, or the use of a set of preferred outcomes.

Using energy intensity factors which are based on area-wide average values and the assumed presence of specific end use energy technologies for space heating, industrial processes, transportation vehicles, etc., the set, of projected land use activities are converted into a set of energy demands, some of which are converled to spcoitidi fiuts,

The description of the community or regional energy system which is coupled, loosely at times, to energy demands consists of a projected set of energy capacities and fuel requirements, conversion facilities, fuel distribution and delivery systems, and if applicable, import. accommodations. It also contains a description of the specific energy supply technologies employed. Finally, it documents the fuel imports into the region which represents in essence the loading on the external energy system.

The initial step in utilizing the procedures and data described in this workbook is to prepare a basic set of energy and land use data and information applicable to the area under consideration. Aside from the local input on projected land usc activities and supply.mdistribution descriptors, all the other technical coefficlents ieeded to asgemble this data base are provided in the workbook in the form of tables, graphs, and charts. For example, In the abatracts from The Planners' Energy Workbook shown in Table III, the land use planner need initially supply only the "land use activity" data, which is normally contained in local land use plans and published census data. Region-specific degree-day lata for huating nnd cooling seasons, efficiencies of energy end use devices and equipment, and other information to carry through the arlalysis is found within the workbook itself. In certain cases, where verification of the technical coefficients is judged to be necessary, procedures are described for carrying this out. Once this basic data and information 
TABLE III

ABSTRAZTS OF RESIDENTIAL AND TRANSPORTATION WORKSHEETS*

Note: Energy Demard of Consumption in $10^{12}$ Bty/yr.
Unit Energy Demand of Consumption in $10^{6}$ Btu/yr per dwelling unit.

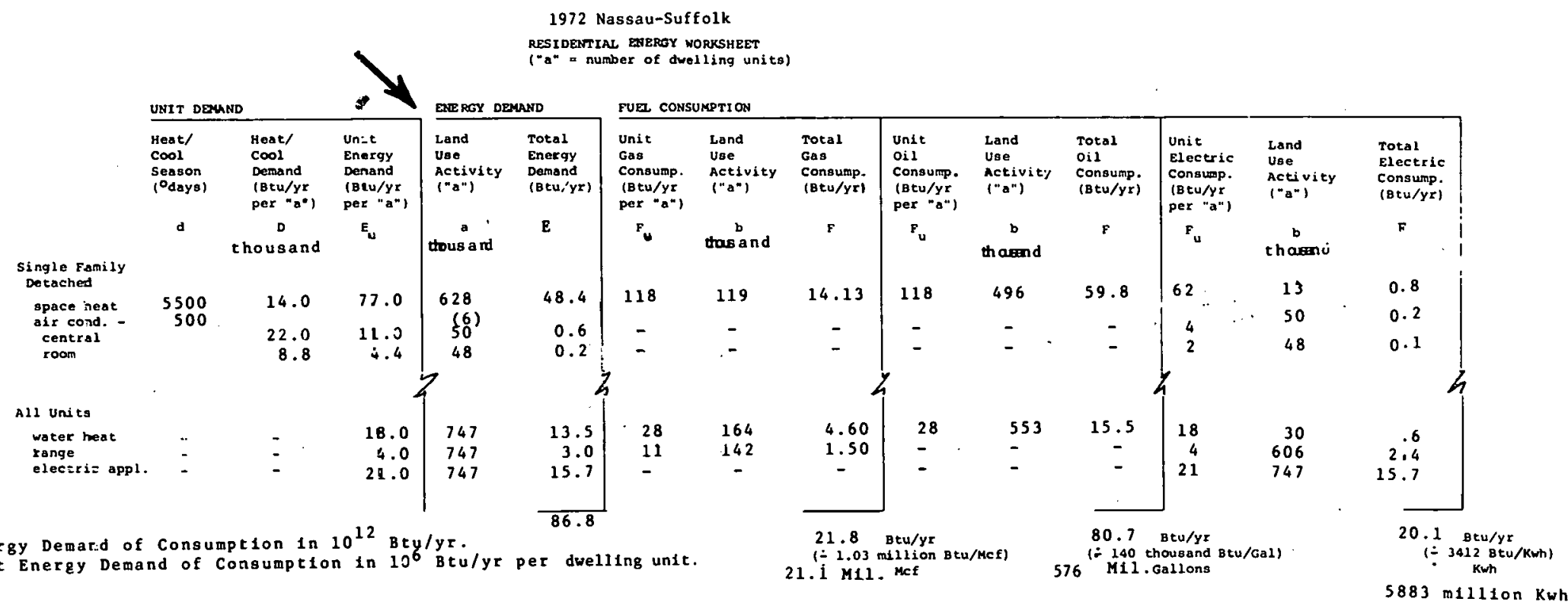

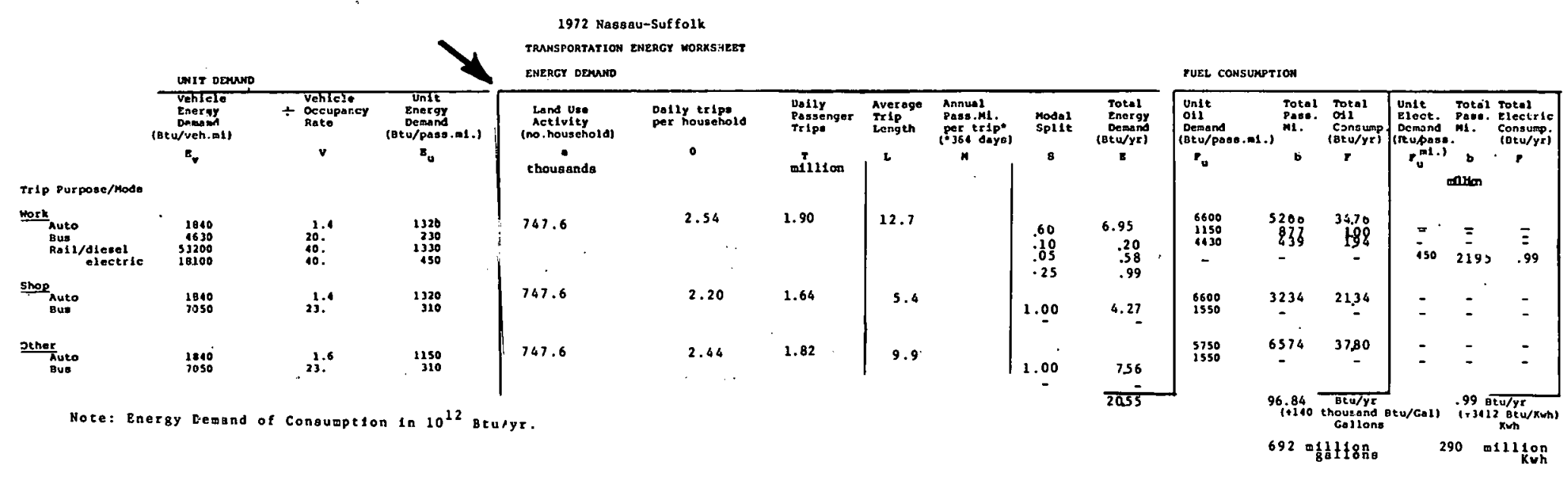

*From the Planners' Energy Worl:book. 
base has been established, the user can then begin to evaluate the impacts of either land use development on the energy system or the reverse. In actual practice, the level of detail needed to assess these impacts will depend on the specific application.

There are several types of problems and concerns that may be addressed by the framework and data base described in the workbook.

1. Developing Guidelines for Energy-Efficient Land Use Development. An increasing number of communities in the country are now acknowledging that they require guidelines to insure that the remaining developable land within their jurisdictlun is utilized in a manner that coincides with community preferences and interests. One contributing factor to formulating such guidelines is the efficient use of energy in the management of community resources. Communities or regions may wish to explore the energy use patterns associated with a variety of possible development scenarios.

2. Evaluating Utility Demand Projections on the Basis of Expected Trends in Community Land Use Development or Proposed Land Use Plans:

Citizen and consumer participation in the planning for utility siting of new electric generating stations has increased substantially over the past scveral years. A significant part of the dialogue between utility and consumer reprusentontives centers on the interplay between the projections for electrical demand and future communtty growth and development. Because of the central role that both energy and the use of land play in the life of the community an analytical. tool for examining the tradeoffs between the two provides a useful structure on which to base thuse dincussions. Thus, planning boards and/or ulilitica may wish to evaluate utility demand projections on the basls ut expected trends in land use development or specifically proposed land use plans. 
Utility demand projections have traditionally not been based on demands derived from land use activity projections. On the other hand, they usually contain a great deal of region-specific data on such things as appliance saturation, seasonal use of electrical space conditioning devices, and the electrical demands due to local manufacturing processes. They are also more sensitive to economic factors which contribute to the final demand. Combining land use input with the traditional basis for electrical demand projections provides both a broader data base and a useful format for coupling these demands with a community's preference with respect to its future development. If access is available to local utility data, the energy intensity coefficients can be refined and validated in a more precise fashion. One can also include both the influence of developing energy end-use technologies, fuel substitution possibilities, and price elasticities to improve the estimation of fuel requirements.

3. Responding to Federal and State Energy Legislation and Directives and Assessing their Land-Use Implications:

The Federal Energy Conservation Act of 1976 stipulates that states must formulate plans for specific actions together with supporting data bases for reducing the demand on scarce fuel supplies. Implementation of this and other federal legislation will take a number of forms. Some states are considering the enactment of legislation which will require local communities to compile their current and projected energy expenditure in order to ascertain specific measures which can reduce energy consumption. Others are in the process of reviewing highway construction plans and mass transit subsidies to take account of their energy implications. Building code revisions and tax abatement to encourage the use of new construction materials, installation of solar heating and cooline, and retrofiting of exlsting homes have been passed. Some of these state and federal energy conservation measures will require specific responses on the part 
of local governments and municipalities. Others will have long term impacts on local land use development patterns. The community or regional planning board, or officiating body, may wish to either set up a data base to monitor community or regional energy consumption patterns, assess the likely impacts of specific state and federal actions, or to respond to specific directives by appropriate state agencies. While the detailed approach used in each of Lhese illuotrative areas will vary, the procedures and information base described in this workbook offer local planners a starting point for their study. For example, if scenarios for future development can be documented in terms of even a crude approximation of their implied land use mixes and spatial arrangement, energy intensity coefficients cal- culated for local conditions and the worksheets can be used to estimate their energy and fuel budgets and correlate them with zoning policies in the residential, commercial, and industrial sectors and the resulting implicutions for energy necdo in the transportation sector.

Although the use of the workbook for responding to federal and state policey is dependent on the speritic polley did/or action, in generul oile musl cugment the appros.shes outlined above with those used in analyzing impacts in the individual land use sectors, if the desired outcome is a detailed response ur imlact croluation. For example, analysis of building code motifirations, retrofit measures, or use of solar technologies will require the use of engineering and architectural models sensitive to energy use factors. Policies and legislation oriented toward highway mass transit w1ll require tronkportation and economic models that deal with consumer choices. In many cases, however, a broad energy overview is desired either as a starting point for a more extensive detailed analysis or as a 
means of satisfying state and federal information requirements. In such cases, the workbook procedures outlined here would probably be sufficient.

E. Energy Assessment of Land Use Development Plans*

As noted in the discussion of the systems approach earlier, the primary purpose of the land use-energy utilization study is the development and testing of the systems framework, methodologies, and support bases of data and information for evaluating energy impacts of land use development. The work has not been directed toward the determination of energy "optimal" land use, but rather techniques for assessing the energy implications of existing or proposed land use plans and community designs.

The Long Island Nassau-Suffolk region was a testing ground for the methods and concepts being developed, which was dictated in part by the accessibility of data and information related to existing land use. development, a history of rapid growth, the existence of a large undeveloped area, and the presence of a relatively detailed master plan. That plan summarizes both the regional development goals and expectations with respect to regional growth, and the preferences of the local planning boards with regard to the major spatial allocations of land use and mix of industries which are basic inputs to the systems framework.

The current population of the Nassau-Suffolk region is approximately $2,500,000$ with a further population increase of $1,500,000$ expected by the year 2000. The region now contains a mix of areas of high population density close to New York City and semi-rural areas in the eastern tip of Lnng Island. It is this edstern sector of the region that is currently undergoing a major change in the pattern of its land use development. Areas that were once entirely agricultural are being taken over by housing developments, shopping centers, and industrial parks. At present, the overall pattern of land use in the Nassau-Suffolk region consists of mostly detached single-family homes with a variety of retail types, offices,

T.O. Carroll, et al., The Planners' Energy Workbook, BNL/SUNY Report, BNI 50633 
and industrial parks scattered along major highways and interconnecting roads. With current residential, commercial, and industrial sites so thinly interspersed and no basic system of public transportation, the private automobile forms an essential part of the "Long Island" lifestyle.

Although the results obtained in this analysis are specific to this region, they can have significant implications for the country as a whole, for in a very real sense, the changing character of land use patterns rapidly taking place in the Nassau-Suffolk region is typical of that found in many similar regions of the country close lu major urban centers. In one respect, however, the region may be highly unusual. Considerable time and effort has been expended in studies intended to examine the alternatives for future economic development in the area, its projected employment and occupational mix, the use of clustered housing, industrial and commercial activities. Furthermore, public officials in this area have demonstrated a willingness to consider the interspersion of high and low density land uses. These documented goals and preferences are reflected in the bi-county master plan.

Not only does Nassau-Suffolk resemble many regions of the country in its current pattern of growth and land use development, it is alsn typical nf many energy importing sections of the country. Natural gas used in the region is derived mostly from domestic sources delivered to the region by trans-continental pipelines. Recently, as domestio sources of gas have become more restricted, increased attention has turned to the construction of storage facilities on the island for LNG. Imported oil from non-domestic sources is the primary fuel used in the region. Because of environmental considerations and past regional preferences, coal utilization in the region has remained small. Essentially all the electricity supplied to the NassauSuffolk region is produced by a single utility with all ils electric genera-

*

We are indebted to the staff of the Nassau-Suffolk Regional Planning Commission and the Nassau and Suffolk County Planning Boards for their time and efforts spent in familiarizing us with the results and analysis that went into producing the master plan. We are espectially thankful to $\mathrm{Dr}$. Lee Koppelman for the interest he has shown in our study. 
ing facilities located on the island. Nuclear-fueled electricity is due to become a major source of the region's electric supply over the next decade. The scheduled construction of new reactors, new oil and LNG storage facilities, and new transmission lines in the Nassau-Suffolk region has produced a climate in which energy conservation is viewed as a means of reducing some of the deleterious side-effects of increasing the capacities of the region's energy supply-distribution system.

Two alternative scenarios describe the potential patterns of future land use development in the Nassau-Suffolk region through the year 2000 . The projected values for the basic regional development parameters are the same for both scenarios, however the projected spatial pattern of development is quite different. A "Continuation of Urban Sprawl" (US) scenario assumes the continuation of existing regional patterns of land use development. More specifically, this means a continuing predominance of single-family detached housing. We assume the spatial pattern of development of commercial floorspace will correspond to what has occurred in the past; that is, it is widely dispersed along primary and secondary roads. New road construction is assumed to develop in the quasi-random pattern of past years.

A "Corridors, Clusters and Centers" (CCC) scenario is based on the design for new area development published in the 1985 master plan by the Nassau-Suffolk Regional Planning Commission. Future development is seen as occurring primarily in the undeveloped eastern portion of Long Island where it will be confined for the most part to clustered residential neighborhoods and medium and large multi-use centers which will provide the service, commercial, transportation, education, health, recreation, and some of the employment needs of the region's inhabitants. In order to preserve the attractive coastal areas of this region for recreational purposes, major transit corridors are restricted to the center spine of the Island. The basic location of the corridors, clustcrs, nand centers which will serve the needs of the projected population in the newly developed areas of the Nassau-Suffolk region are set down in the regional master plan. The plan also specifies the approximate size of the clusters and centers and mix of activities. For the residential sector, 
this places a restriction on both the number and the location of single family detached dwellings. New construction of the other dwelling types falls into other residential categories -- single-family attached, low rise and high-rise apartments -- located in the designated centers and clusters. With respect to the commercial sector, the major difference is the shift of retail commercial floorspace development to malls located in or near the centers and clusters. The presence of projected centers and clusters in this scenario leads to increased use of mass transportation and to changes in the total vehicle miles traveled brought about by the greater density of land use activities.

The patterns of energy consumption for the two alternative spatial patterns of future land use are shown in Table IV. Although such an analysis reflects only projected, or potential energy shifts and should be considered tentative, some interesting conclusions can be drawn. One might observe first of all that the total fuel savings between the US and CCC scenarios, namely $39.1 \times 10^{12} \mathrm{Btu}$, represents some $8 \%$ of the total 2000 demand. The importance of that savings is augmented by the fact that most of it will act to reduce the imported fraction of oil supply. That savings, furthermore, will be immense beyond the year 2000 as the land use pattern in existence at the beginning of the planning period has less and less influence upon total demand. Not unexpectedly, it is the transportation sector in which there is the largest change in energy consumption. between the sprawl and CCC scenarios, an impressive 52\%. This energy savings results primarily from decreases in the average trip length. for work purposes associated with increasing employment opportunities in the developing centers and some reduction in shopping distances. Though some shifts toward mass transit are envisioned, this contributes relatively little to reduced energy need for the private transportation sector as a whole. In addition to that savings due to changes in the 2000 spatial land use pattern, there is an even larger savings $77 \times 10^{12} \mathrm{Btu}$, resulting from improvements in miles per gallon. To first order, these two effects are independent and are considered so in the scenarios.* Their combined strength is such that the total transportation

* They are interdependent only to the degree that lower costs of automobile travel, produced by improved mileage, reduces the incentives to create a CCC type of land use configuration. 
Table IV

SUMMARY OF LAND USE ENERGY SCENARIOS FOR NASSAU-SUFFOLK

FUEL USE ${ }^{\mathrm{a}}$ IN $10^{12}$ Btu

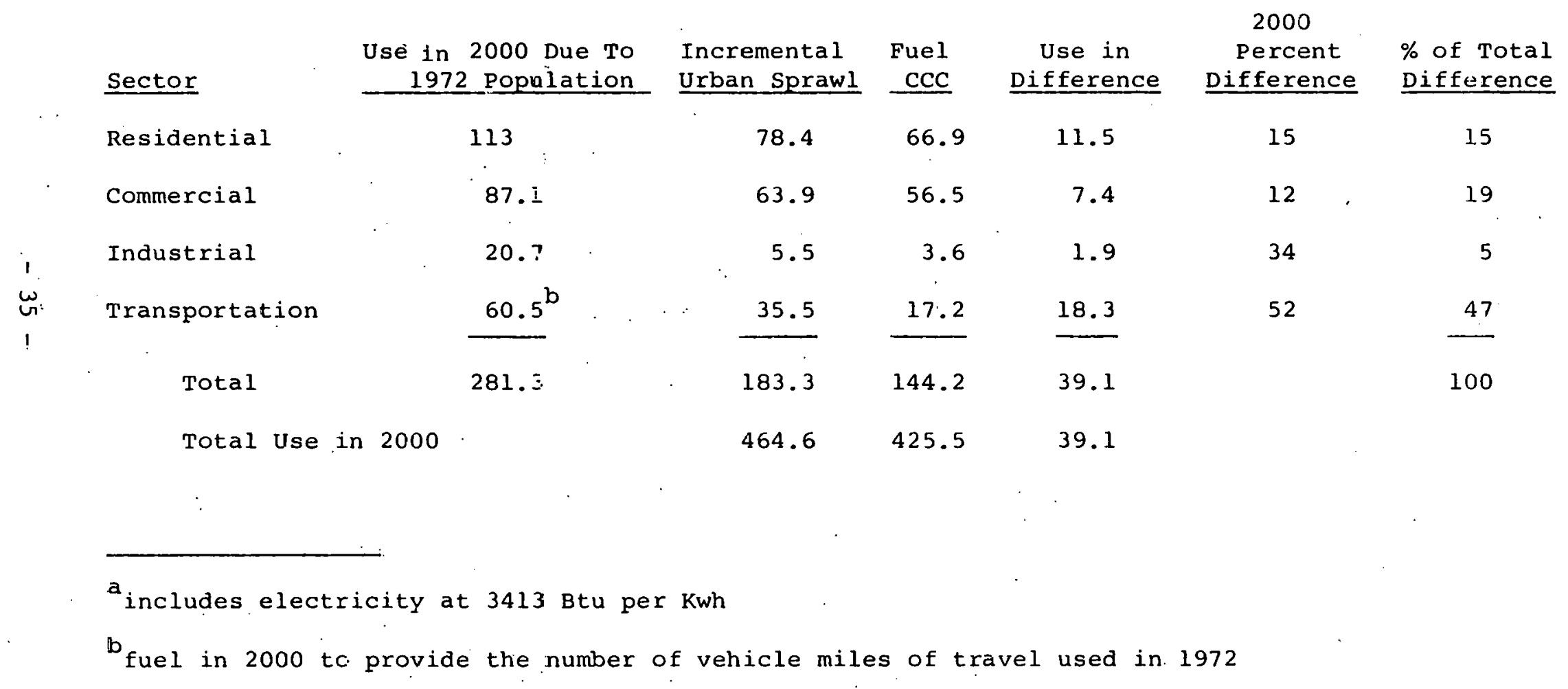


energy consumption in 2000 in the CCC scenario is only $65 \%$ of the consumption in 1972 although the population has risen by $65 \%$.

The differences in residential and commercial energy use associated with the trends toward attached housing and multi-purpose mall development, respectively, between the two scenarios are very similar at $15 \%$ and $12 \%$. Although the percentage changes are fairly small compared to the $52 \%$ effect in the transportation sector, the absolute magnitude of those sectors results in these changes representing a relatively large fraction together about half, of the aggregate difference in energy consumption between scenarios.

Thus, present planning practices and design philosophies utilized in the preparation of area land use plans in a region such as Long Island suggest that total incremental energy consumption can be reduced by $15-25 \%$ by altered patterns of growth. While the largest percentage differences may appear in the transportation sector, larger absolute savings may result from different residential and comercial construction patterns associated with more clustered development. To the degree to which savings in petroleum are more important than savings in other fuels, the transportation sector, essentially completely dependent on oil, becomes more prominent.

In an effort to develop a better understanding of the origins of energy shifts associated with the spatial pattern of land use both in the Long Island region and in general, the land use-energy simulation model was calibrated and run for the Nassau-Suffolk comprehensive plan as well as for a number of hypothetical development alternatives representative of potential land use growth. The results, while suggestive of generic land use-energy utilization relationships, indicate the need for further study with the model. For example, the trade-off between work and shopping trip vehicle-miles in the region is somewhat complex. Area development with centralized employment leads to work trips which are long, whereas shop trips remain short. For dispersed employment, where a central region of high basic industrial employment is surrounded by significant levels of dispersed suburban employment, the work trip length becomes less, but 
shop trips become longer. Such. shifts in trip lengths and associated transportation energy requirements result from residential zoning and commercial agglomeration considerations. That is lower population densities cannot support commercial development at more than a limited number of sites. Overall, the least total vehicle miles per household occurs for the case of some modest suburban, employment. At present, it is difficult to summarize such analyses into simplified planning design considerations. Additional exploration with the computer model and field studies in a variety of communities using The Planners' Energy Workbook and other data and information prepared in this study will be required to clarify the magnitude and direction of land use and energy utilization relationships. 
THIS PAGE

\section{WAS INTENTIONALLY LEFT BLANK}


It is evident from our discussions that as an area of investigation and research, much remains to be done to elucidate the complicated interdependencies between land use and energy utilization. What we have accomplished is an initial structuring of the problem. On the other hand, the recent increase in interest in establishing new ways for the United States to achieve energy conservation suggests that actions will be taken in the near future to tie land use development to national and local targets for conservation. In what follows, we suggest a combination of research, data collection, demonstration, and policy-related efforts aimed at both increasing our understanding of the land use-energy equation and at effecting changes in current land use planning practices.

\section{A. Land Use-Energy Analysis Demonstrations}

For a variety of reasons, only some of which are related to energy, a number of regions and communities in the country have indicated interest in incorporating energy analysis into their planning efforts. Efforts to aid these areas in utilizing the methodologies outlined in this report to chart the future course of their development would have obvious benefits to federal energy programs. In addition to acting as laboratories for refining the analytical methodologies, such activities would help to convince planners in other parts of the country to adopt energy planning tools for their own use. Such activities would stimuläte interest in the energy 1mpacts of land use planning. More 1mportantly, within the planning professions such activities would begin to develop the understanding of the role of energy in community design and land use planning which will be necessary for effective utilization of federal and state conservation and advanced technology initiatives.

B. Guidelines for Energy Conserving Land Use Development

A number of analyses, including our own, have demonstrated that through the propitious use of land, significant energy reductions aan be made in 
projected future energy expenditures over that associated with conventional land use configurations. Were the federal government and interested state governments ta prepare specific guidelines which would define steps that local governments could take to bring about more energy conserving uses of land, it would aid public interest and citizen groups, developers, and planning boards in making judgments on the directions they would like to see local land use development take. While it is not anticipated that these guidelines would constitute anything other than suggested actions and policies on the part of the federal or state government, they would help in categorizing the numerous and interactive land use decisions in terms of their compatibility with a more energy efficient overall pattern.

\section{Energy Accounting Measures and Indices}

As noted in Section III-A of this report, the absence of measurable indices to evaluate energy impacts of land use arrangements in terms of their local and national costs and benefits will make it difficult to assess the trade-offs between alternate land use development patterns. Their absence also poses difficulties for either state or federal governments to coordinate actions taken by agencies responsible for setting housing codes, designing road networks, siting new energy facilities a.I of which influence the nature of the land use-energy interdependence: Research is needed to establish a proper basis for establishing such indices.

D. Land Use-Energy Relationships and Environmental Factors

In many urban centers, the major land use activities which are responsible for the production and consumption of energy are also responsible for the primary generation of environmental pollutants. Although it is evident that there are many land use actions that could be taken to make energy utilization more efficient and which would be compatible with reducing pollutant levels, as yet there has been little detailed analyses of the interactions between these two societal concerns in these urban areas. A coordinated program between approprlate federal agencies to establish a common methodology and data base for formulating an energy component to the environmental regulations and control indices should be established. 


\section{E. Land Use and New Energy Technologies}

Although land use patterns strongly determine the magnitude and character of a major component of the energy demand in the highly populated urban areas of the country, their final form will grow increasingly sensitive to new energy technologies expected to come into use over the next several decades. The electric car, solar heating and cooling, and the imposition of new building standards and construction processes are examples of technologies that will influence land use patterns. What is far from obvious are the overall energy demands that will be generated by the resulting land use development. It is entirely possible, for example, that as a result of the wider geographic dispersion of land use that may result from the use of solar energy, transportation energy requirements could increase. Assessments of the land use-energy impacts of these and other technologies should be carried out in order to evaluate their overall demand on. all energy fuels and to anticipate the land use patterns most favorable to realizing their potential.

F. National Land Use Trends and Projected National Energy Demands Declining family size, shifting migration patterns toward the sunbelt, increasing use of recreational facilities, continuing dispersion of industrial manufacturing, and other major trends in the economic and social life of the nation have received recent attention. Those promise to bring about significant structural changes in the patterns of growth and land use development in urban and suburban areas. For exarule, the present practice of siting light manufacturing activities in largely rural settings tends to cause nucleation of many small, interconnected growth centers as opposed to more centralized expansion of existing population and employment centers. Such national land use trends certainly are strong determinants of the future potential for decentralized energy conversion technologies, district heating, and other advanced energy systems as well as of energy conservation possibilities which might be realized through such changes as construction practices and standards or transportation system modifications. Equally important, 
these national land use trends will establish future levels of energy consumption which reflect a changed set of energy. end use demands associated with the personal energy requirements and industrial needs of a nationwide population distribution shifting south and west. An assessment of the energy utilization implications of national land use trends should be carried out to identify the extent to which these changing patterns of both land use and energy are compatible with federal energy technology and conservation initiatives and goals.

G. Lifestyle Analysis

A natural extension of the work presented in this series of reports and other recent work could be a more wide-ranging examination of the energy implications of alternative life styles. Here we have established the analytical and technical basis for such an analysis. This should now be combined with a more speculative investigation of a variety of future social patterns including considerations of social roles, time allocation, and socioeconomic distribution as a basis for understanding the range of possible future energy patterns. 


\section{FUTURE SIGNIFICANCE OF LAND USE AND ENERGY UTILIZATION ANALYSIS}

Over the past few years, we have come to realize how difficult it is to understand the details of a society's energy use and to formulate policies to affect that use. As usual, when confronted with analytical difficulty, we take a reductionist approach. We divide energy use into a number of sectors -- residential, commercial, industrial, transportation -- and analyze particular energy uses in each sector. For the most pert, this has been a successfull approach. However, its shortcoming is that it neglects the fabric, the structure that ties all energy uses together. That structure is in part physical -- the physical patterns of development and growth -- and in part social -- the way people spend their time and money. Lifestyle, an unfortunate but useful term, is lost through disection and, as a result, changes in life-style can not be considered in policy analysis.

The significance of energy /and use analysis is that it must consider the structure of all energy uses. It stands back far enough so that physical and social patterns are revealed. This is not to say that details can be ignored. In fact, the details of energy use in all the consuming sectors must be considered. For example, to understand the energy impacts of altered residential patterns, one must understand the details of the efficiency of the use of various fuels in different housing types and the energy used in constructing that housing. But the analysis must proceed beyond that point to understand the relationship between housing types, transportation patterns, and energy use in various transporation modes.

Energy-land use analysis has an important future role in providing an integrative framework for public policy making. In a political world eager for immediate results and short term impacts, there is a danger that this type of analysis will be neglected or given a low priority. But our energy problems are long term. They 
are also intimately related to the way in which our society is structured and the way in which we pattern our lives. Energyland use analysis can develop in ways which help us to understand those structures and patterns and ultimately to establish policies which more accurately anticipate the needs and desires of the future. 